\title{
Electrophysiological study of dystrophia myotonica
}

\author{
A. J. MCCOMAS, M. J. CAMPBELL, AND R. E. P. SICA \\ From the Muscular Dystrophy Research Laboratories, Newcastle General Hospital, Newcastle upon Tyne
}

SUMMARY A comprehensive electrophysiological study has been made of the extensor digitorum brevis muscle and its motor innervation in 17 patients with dystrophia myotonica. The mean contraction and half-relaxation times were prolonged in the isometric twitches of dystrophic muscles. Decremental responses to repetitive motor nerve stimulation were found in two patients. All the terminal latency measurements were normal and only one patient had a reduced nerve conduction velocity. As the patients aged their muscles became weaker, due to a progressive loss of motor units. This finding, and the normal sizes of many surviving motor units, suggested that the muscle changes resulted from a primary defect of motor innervation.

The aim of the present study has been to obtain detailed information concerning nerve and muscle function in dystrophia myotonica. Our approach has been to make most of the observations on a single muscle and its motor nerve supply, and then to correlate the experimental findings as fully as possible. The study has involved not only conventional procedures, such as the determination of motor nerve conduction velocity and the neuromuscular responses to repetitive stimulation, but also two more specialized techniques. One of these permits the characteristics of the isometric muscle twitch to be investigated (Sica and McComas, 1971), while the other enables an estimate to be made of the number of motor units in a muscle (McComas, Fawcett, Campbell, and Sica, 1971). The most important finding of this study was that the increasing weakness resulted from the loss of successive motor units. The significance of this finding has been considered in relation to the pathogenesis of dystrophia myotonica. A preliminary account of this work has been given elsewhere (Campbell, McComas, and Sica, 1970).

\section{METHODS}

SUBJECTS There were six female and 11 male patients. Their ages ranged from 17 to 63 and in all cases the clinical and electromyographic findings were characteristic of dystrophia myotonica. In general, the youngest patients were affected least by the disease; the two oldest women, aged 59 and 63 respectively, were severely incapacitated and three men were unable to work because of their disabilities. A population of 27 male and 21 female subjects aged 17 to 58 and with no evidence of disease affecting the legs was drawn upon for controb observations.

STIMULATING AND RECORDING TECHNIQUES Three typ@ $\mathbb{N}$ of electrophysiological study involved the extensol digitorum brevis (EDB) muscle.

1. The number of motor units was estimated by the $I$ method of McComas, Fawcett, Campbell, and Sig (1971).

2. The isometric twitch of the extensor hallucis brevis that is, the most medial part of EDB-was investigate using the technique of Sica and McComas (1971).

3. The conduction velocities of motor nerve fibres in the deep peroneal nerve were determined from measurements of the latencies of potentials evoked in EDB after nerve stimulation at the ankle and at the head of the fibula. The stimuli were rectangular voltage pulses, $50 \mu \mathrm{sec}$ in duration, and were delivered through two chlorided silver electrodes covered with lint soaked in $10 \%$ sodium chloride solution. The electrodes presented circular surface areas, $10 \mathrm{~mm}$ in diameter, and were separated by $2 \mathrm{~cm}$ in a Perspex holder. The evoked muscle potentials were usually recorded with a coaxial needle electrode (Medelec Ltd.) and occasionally with the surface electrodes employed in the estimation of the number of motor units. The latencies of the amplified potentials were measured on a storage oscilloscope (Hewlett Packard Ltd., type 141A) and the central portion of the sweep was expanded in order to permit a temporal resolution of $0.1 \mathrm{msec}$. The leg was warmed by an infra-red lamp so that the temperature of the skin overlying the tibialis anterior muscle, midway between the knee and ankle, was $36-38^{\circ} \mathrm{C}$.

4. Repetitive nerve stimulation. The common peroneal nerve was stimulated at the head of the fibula and evoked potentials were recorded with two silver discs, each $1 \mathrm{~cm}$ in diameter. One electrode was attached to skin over the lower end of the belly of the tibialis anterior muscle, 
while the other was placed over the tibia; an earth electrode lay between the recording electrodes and the cathodal stimulating electrode. The following sequences of stimuli were employed; four stimuli at $3 / \mathrm{sec} ; 180$ stimuli at 2/sec (cf. Slomić, Rosenfalck, and Buchthal, 1968), and 26 stimuli at $50 / \mathrm{sec}$; sometimes other frequencies were used as well. The stimuli were at least $150 \%$ of the maximal intensity and the evoked responses were judged abnormal if a decrement exceeded $5 \%$ at rates of 2 or $3 \mathrm{stimuli} / \mathrm{sec}$, or $15 \%$ at $50 \mathrm{stimuli} / \mathrm{sec}$.

STATISTICAL TREATMENT Means have been expressed with standard deviations throughout the text. Significances of differences between means were calculated using the Student $t$ test.

\section{RESULTS}

ISOMETRIC TWITCH OF EXTENSOR HALLUCIS BREVIS (ЕHB) Figure 1 shows the maximal isometric twitches and evoked potentials recorded in two patients with dystrophia myotonica. In the electromyogram of the patient M.F. two small myotonic after discharges are evident and may have caused small increases in the contraction and half-relaxation times. In each of the remaining patients it was possible to record a twitch without any evidence of repetitive firing and hence it was justifiable to compare the results in dystrophy with those of the control

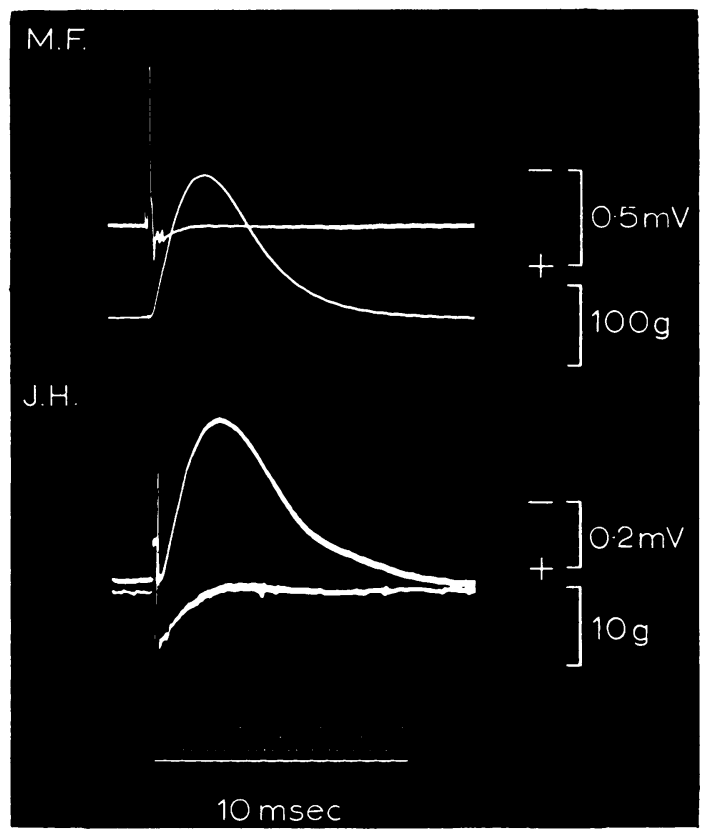

FIG. 1. Isometric twitches of EHB muscles in two patients with dystrophia myotonica. See text. population. It can be seen that in the patient M.F. the twitch was of normal amplitude and time course; thus the active tension was $180 \mathrm{~g}$, while the contraction and half-relaxation times were 68 and 73 msec respectively. The muscle of the patient J.H. was very much weaker and the maximum twitch tension amounted to only $20 \mathrm{~g}$; the contraction and half-relaxation times ( 77 and $80 \mathrm{msec}$ respectively) were at the upper limits of the normal ranges.

In Fig. 2(a) the dystrophic twitch tensions have been plotted as a function of the patient's age and it is apparent that the two factors are related. As expected, the weakest muscles occurred in older patients who had suffered longest from the disease. From Fig. 2 (b, c) it appeared that older patients also tended to have the slowest twitches. Although only three of the contraction times fell outside the normal range, the mean value of the pooled results $(71 \cdot 0 \pm 10 \cdot 0 \mathrm{msec})$ was nevertheless significantly different from that of the control population $(63.4 \pm$ $7.2 \mathrm{msec}, \mathrm{P}<0.001$; Fig. 3(a)). On the other hand many of the dystrophic half-relaxation times were strikingly prolonged and the mean value of $82.2 \pm$ $19 \cdot 1 \mathrm{msec}$ differed markedly from the control mean of $52.5 \pm 9.7 \mathrm{msec}(\mathrm{P}=<0.001$; Fig. 3(b)).

ESTIMATED NUMBER OF MOTOR UNITS IN EDB Figure 4 shows incremental muscle responses in EDB after stimuli which were carefully graded above threshold strength. In this patient the number of motor units in EDB was estimated to be only 27 and was therefore well below the lower limit of the control range (121); of the 17 patients examined, low values were observed in 12 (Fig. 6). It can be seen from Fig. 4 that, although there was a reduced number of motor units in this patient, the potential amplitudes of the surviving units were within the normal range. This last consideration was of great theoretical interest (see Discussion) and has been developed further in Fig. 5 where the amplitudes of all the motor unit potentials recorded in the 17 dystrophic patients have been compared with those in normal subjects. It is apparent that, although the mean size of the dystrophic unit potentials was significantly reduced, the majority of the potentials were still within the normal range. Furthermore, the mean size of the unit potentials in 'late' dystrophy was not significantly smaller than that in 'early' dystrophy-that is, in those patients in whom the twitch tensions were still within normal limits. Finally, in Fig. 5 the distribution of results was such as to suggest that only a small number of units were likely to have generated potentials too small to have been discriminated from noise-that is, less than $4 \mu \mathrm{V}$. In other words it was probable that the small estimates of numbers of units resulted from the complete disappearance 

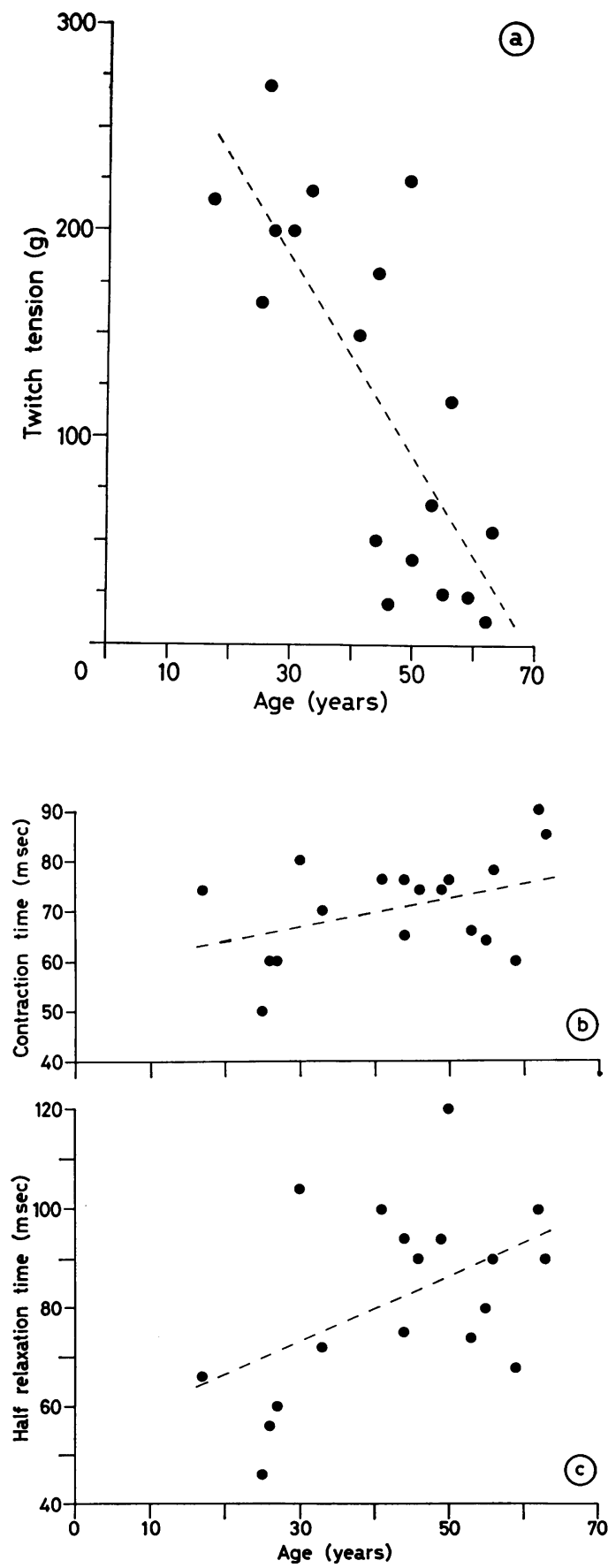

FIG. 2. Twitch parameters of EHB muscles in 17 patients with dystrophia myotonica, plotted as a function of age. (a) Twitch tension ( $r=-0.77)$; (b) contraction time $(r=0.43)$; (c) half-relaxation time $(r=0.50)$.

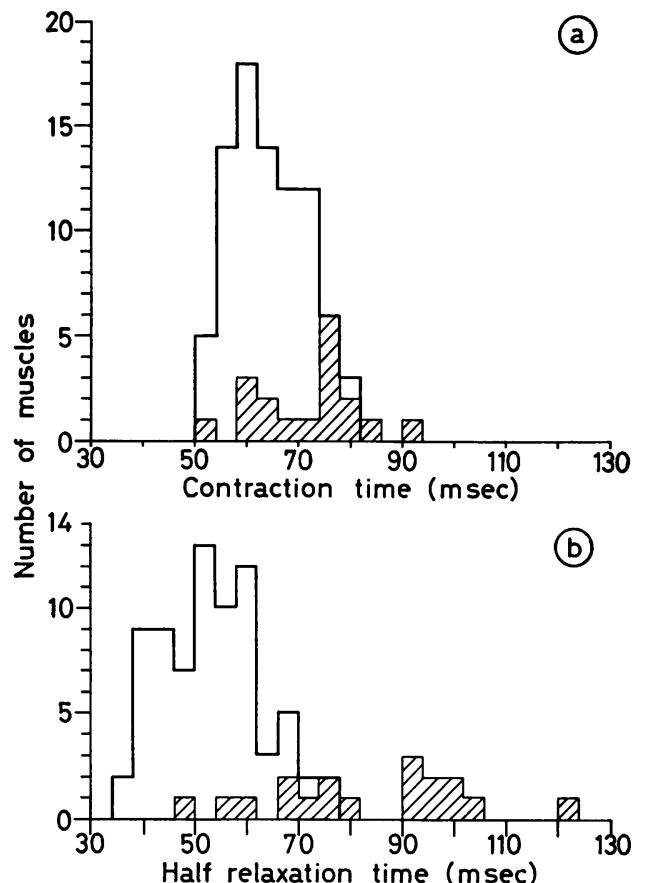

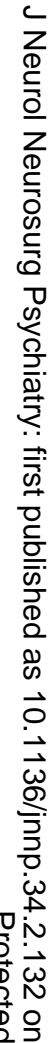

FIG. 3. Twitch velocities in 17 patients with dystrophio myotonica compared with those in 45 controls $(73$ muscles) (a) contraction time; (b) half-relaxation time. Me요을 dystrophic contraction and half-relaxation times were $\rightarrow$ $71 \cdot 0 \pm 10 \cdot 0$ and $82 \cdot 2 \pm 19 \cdot 1 \mathrm{msec}$ respectively, white corresponding control values were $63.4 \pm 7.2$ and 52.5 . 9.7 msec; in each case $P=<0.001$. Dystrophic and control values in hatched and open columns respectively.

of motor units rather than from a failure to detect a $\unrhd$ 'hidden' population of very small ones. From Fig. $6 \overrightarrow{\overrightarrow{0}}$ it can be seen that there was a strong correlation 3 between number of surviving units and the twitch tension which could be developed by a dystrophic muscle or, alternatively, the age of the patient. If the regression line in Fig. 6(a) is extrapolated it would suggest that approximately half of the patients with dystrophia myotonica would have lost all the motor units in EDB if they had lived to the age of 60.

MOTOR NERVE CONDUCTION VELOCITIES The conduc- $\bigcirc$ tion velocities of the fastest conducting motor nerve fibres were measured in the deep peroneal nerves of 14 patients. Only one patient had a value $(35 \mathrm{~m} / \mathrm{sec})$ which was below the lower limit of the normal range 0 for this laboratory $(40 \mathrm{~m} / \mathrm{sec})$ and there was no $\mathrm{N}$ significant difference between the means for the two populations (normal and dystrophic means $48.6 \pm$ $5 \cdot 2$ and $45 \cdot 1 \pm 5 \cdot 2 \mathrm{~m} / \mathrm{sec}$ respectively; $P=>0 \cdot 1)$. 


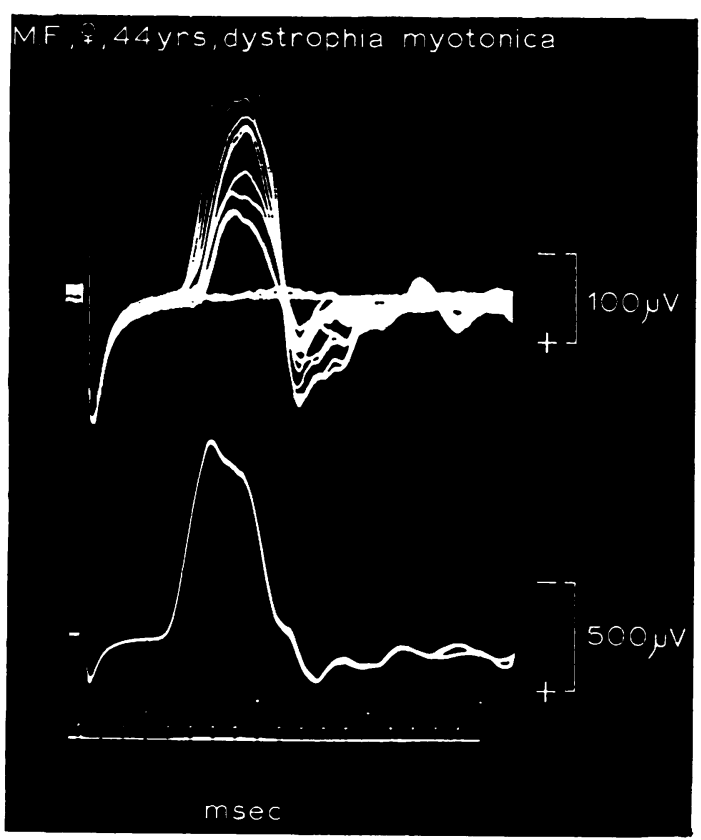

FIG. 4. EDB muscle action potentials evoked in a 44 year old woman with dystrophia myotonica by graded and maximal stimulation of deep peroneal nerve (upper and lower records respectively). In the upper record eight increments can be differentiated; the negative crests of the two largest responses were off the screen. Each incremental response has been superimposed several times. In this muscle 27 motor units were estimated to be present.

In addition measurements were made of the time elapsing between stimulation of the deep peroneal nerve at the ankle and the onset of evoked activity in EDB. All the dystrophic values were found to be within the normal range and, once again, the means for the two populations did not differ significantly (normal $4.0 \pm 0.6$, dystrophic $3.9 \pm 0.8 \mathrm{msec}$, $\mathbf{P}=>0.5$ ).

MUSCLE RESPONSES TO REPETITIVE NERVE STIMULATION Decremental responses to repetitive nerve stimulation were observed in two of the ten patients tested and examples are given in Fig. 7. In this patient there was no difference between the amplitudes of the first and last responses when stimulating at $3 / \mathrm{sec}$; however, at $6 / \mathrm{sec}$ a $27 \%$ decrease was evident while at $10 / \mathrm{sec}$ the decrement amounted to $54 \%$.

\section{DISCUSSION}

The results of the isometric twitch investigation in dystrophia myotonica were predictable in one

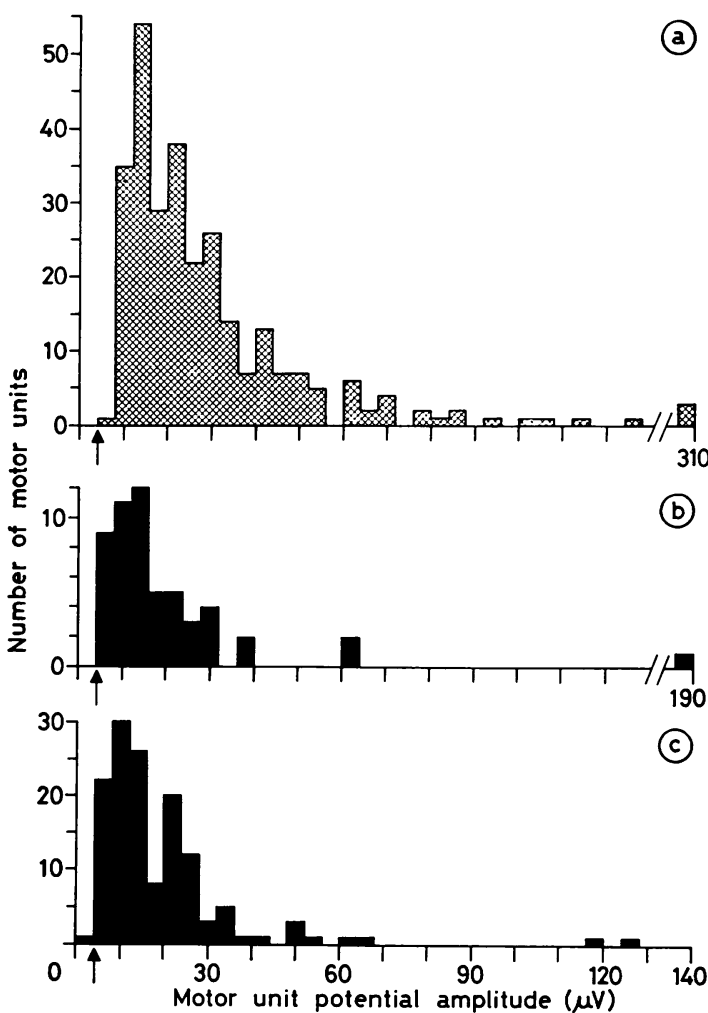

FIG. 5. Amplitudes of motor unit potentials in controls and patients with dystrophia myotonica. (a) Results in 31 controls; mean amplitude $=28.9 \pm 27 \cdot 1 \mu \mathrm{V}, n=283$. (b) Results in five patients with 'early' dystrophy-that is, EHB twitch tensions still in the normal range $(<160 \mathrm{~g})$; mean amplitude $=19.9 \pm 25 \cdot 7 \mu V, n=54$. (c) Results in 12 patients with 'late' dystrophy-that is, twitch tensions below normal range; mean amplitude $18 \cdot 1 \pm 17 \cdot 0 \mu \mathrm{V}$, $n=136$. Arrows indicate noise level $(4 \mu V)$; response increments smaller than this could not have been distinguished reliably. Differences between means in (a) and (b) significant ( $P=<0.001)$; differences between means in (b) and (c) not significant $(P=>0.5)$.

respect, inasmuch as they revealed a weakness which increased with age. On the other hand, it had been anticipated that the time-courses of the dystrophic twitches would shorten due to less severe involvement by the disease process of fibres which were histochemically of type II (Engel, 1965) and which presumably had relatively fast twitches. In fact the opposite was observed, since both the contraction and relaxation phases of the dystrophic twitches were prolonged, though not to the same extents as in the limb-girdle and Duchenne types of dystrophy (Sica and McComas, 1971; McComas, Sica, and 

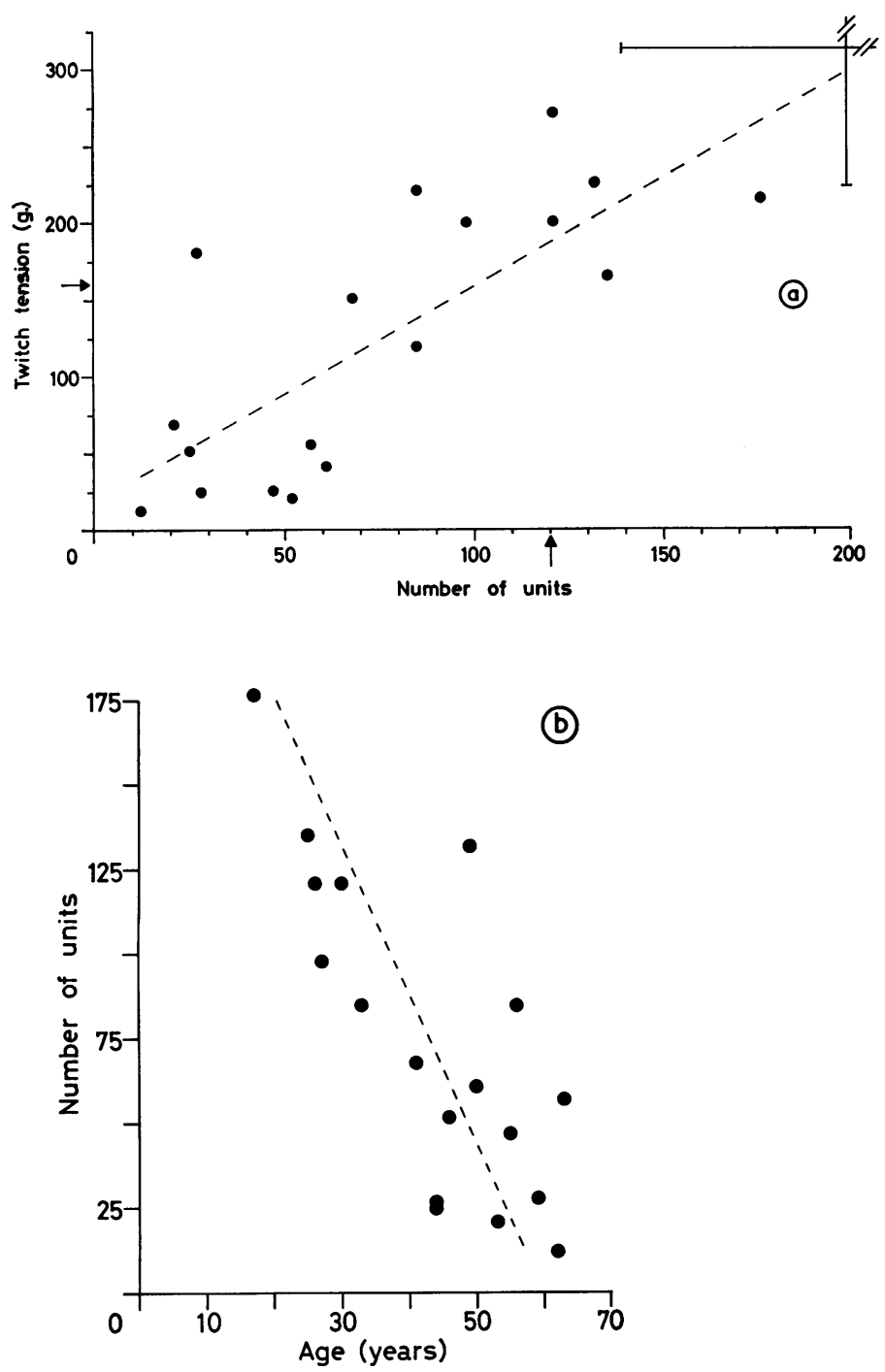

FIG. 6. Numbers of EDB motor units in dystrophia myotonica in relation to (a) EHB twitch tension $(r=0.76)$; (b) age $(r=0.43)$. In (a) the arrows on the two axes indicate the lower limits of the control results. The intersection of the two bars in the top right hand corner denotes the mean number of units and twitch tension; each bar represents one standard deviation from the corresponding mean.
Currie, 1971). It should be noted that in a previous account of this work (Campbell et al., 1970) only the half-relaxation time was reported as abnormal; however, with the inclusion of many more control observations in the present study, the increase in contraction time has also been shown to be statistically significant. In the evaluation of these results the ages of the patients were important, since the fastest twitches tended to occur in the youngest patients. This was not altogether surprising, since type II (fast twitch) fibres would be little affected in a young patient and type I (slow twitch) fibres, although atrophied, would not have regressed to the extent of causing fibrosis and other gross structural derangements in the muscle likely to affect the twitch.

So far as the results of repetitive nerve stimulation are concerned, the finding of myasthenic responses in two patients was not unexpected in view of the changes in end-plate structure which are known to occur in dystrophia myotonica (Coërs and Woolf, 1959; MacDermot, 1961); similar electrophysiological observations have also been made by Ricker and Mertens (1968).

However, the most interesting finding in this study $\widetilde{N}$ was that the number of motor units was reduced in $\underset{\omega}{\mathrm{N}}$ dystrophia myotonica. A fall in the number of motor $\bar{Q}$ 


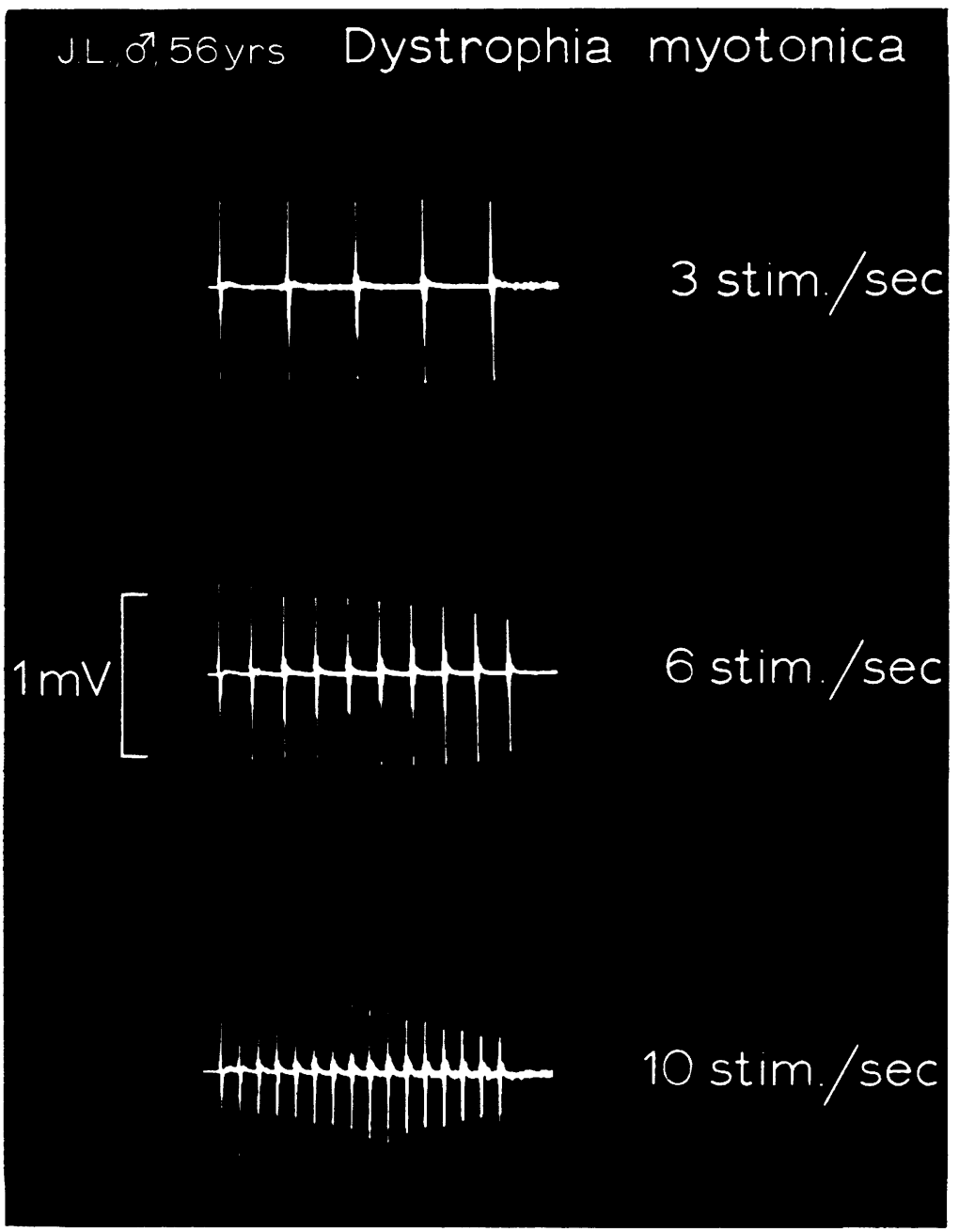

FIG. 7. Responses of tibialis anterior muscle in a 56 year old dystrophic man to stimulation of the common peroneal nerve at different frequencies.

units might also have been suspected from the histological investigation of MacDermot (1961) in which some axons within intramuscular nerve bundles exhibited 'a complete breakdown of nerve fibre substance'. In the present study, the first possibility to be considered was that the 'denervation' of the muscle resulted from inadvertent trauma to peripheral nerves in disabled patients. This explanation was felt to be unlikely for two reasons. Firstly, denervation was already detectable in patients who still had twitch tensions in the normal range, and who were able to walk without difficulty and to lead active lives. Secondly, it is well established that conduction of nerve impulses is usually slowed in regions where nerves have been injured, yet all but one of the measurements of nerve conduction and terminal latency were normal.

The second possibility was that the denervation signalled the eventual destruction of motor units by a primary myopathic process. Thus, on theoretical grounds, it had been expected that one of the early effects of a myopathic process would be a reduction in the number of muscle fibres within a normal population of motor units (Fig. 8, b). As more fibres became involved the motor units would become correspondingly smaller and eventually some units might disappear completely (Fig. 8, c). As more units were lost so surviving ones would be expected to become even smaller (Fig. 8, d). This predicted behaviour would cause the twitch tension and the 


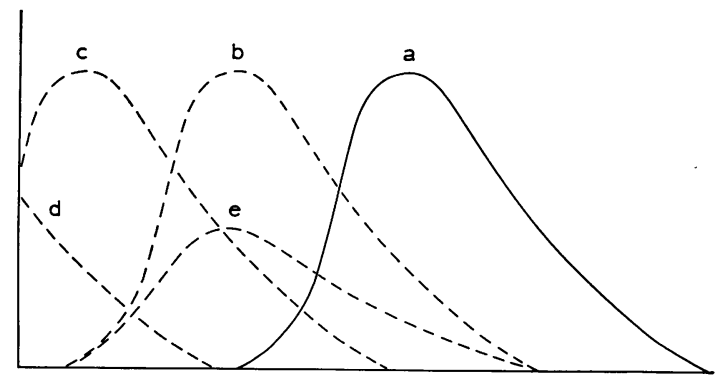

FIG. 8. Theoretical relationships between the number of motor units and their sizes in dystrophia myotonica, assuming that the condition is a primary myopathy (see text); a represents the normal distribution of sizes. Ordinate: number of units. Abscissa: sizes of units.

corresponding number of units in a muscle to exhibit the relationship depicted in Fig. 9 (my).

For comparison, an acute denervating process would cause the relationship, a.d., where the twitch tension is directly proportional to the number of surviving units. Finally, a chronic denervating condition would result in a curve of the form, c.d., since reinnervation would act as a compensatory mechanism by allowing surviving units to enlarge (McComas, Sica, Campbell, and Upton, 1971). In the present experiments some error will have been introduced by measuring the tension developed by only part of EDB. Hence, although individual motor units would be expected to develop approximately

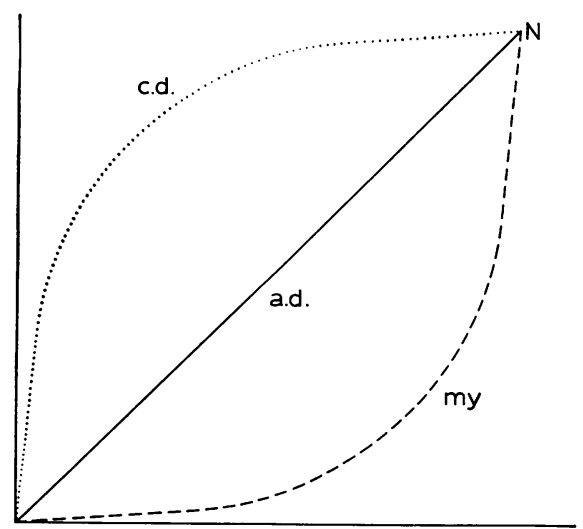

FIG. 9. Theoretical relationship for a muscle between the number of motor units and the twitch tension in three types of disorder: myopathy (my); acute denervation (a.d.), and chronic denervation (c.d.). $\mathrm{N}$ indicates normal values. See text. Ordinate: twitch tension. Abscissa: number of units. four times as much tension as that determined by dividing the EHB tension by the number of units in EDB, this fact would not in itself affect comparisons with control values obtained in the same way. However, if the number of motor units falls in a disease state there is, for statistical as well as pathological reasons, a greater chance of EHB containing $\stackrel{\rho}{\supset}$ an abnormal fraction of the residual innervation to EDB. Nevertheless, with this qualification in mind, the observed findings were more complex than had $\Rightarrow$ been anticipated. Firstly, it did appear from the $\stackrel{\text { of }}{?}$ computed regression line of Fig. 6b that patients possessed a normal number of units during childhood. However, although there was a steady loss of $\frac{\pi}{\vec{T}}$ units in the muscle, the progressive reduction in $\propto$ unit size, which had been anticipated on theoretical grounds, did not take place. Thus, a considerable $\vec{\circ}$ proportion of the motor unit potential amplitudes in late dystrophy were within the normal range $\vec{\omega}$ (Fig. 5) and the mean value, although smaller than normal, did not differ significantly from that in early dystrophy. The twitch tension measurements suggested even more strongly that the surviving motor units retained relatively normal sizes through out the course of the disease. For example it wat $\vec{\omega}$ seen in Fig. 6(a) that, at every stage in the disease, the tension in a dystrophic muscle was directly propog tional to the number of units surviving, while the fact that the extrapolated regression line passed 은 close to the mean control values indicated that the units were of normal size. Judged in terms of the theoretical curves in Fig. 9 it can be seen that the progressive weakness in dystrophia myotonica displayed features more characteristic of neuropathy than myopathy.

In considering the sizes of motor units, however, it is necessary to take into account the possible influence of factors such as fibre diameter and membrane potential on the apparent sizes of units. So far as membrane potential is concerned, it has already been shown that the resting values are reduced in many fibres in dystrophia myotonica (McComas and Mrożek, 1968); if these fibres were innervated (McComas and Mrożek, 1967) they would be expected to develop smaller than normal action currents during excitation. Hence the real size of a dystrophic motor unit would actually have been greater than that suggested by the amplitude of its evoked potential.

The effect of fibre diameter was also important, $\frac{D}{O}$ since a small fibre would develop less tension and a smaller action current than a normal fibre. Therefore $N$ a dystrophic motor unit which had a reduced twitch tension or a small potential may still have had a normal number of muscle fibres. Similarly, an exceptionally large potential or twitch could have been 
developed by a normal number of hypertrophied fibres. Since both atrophied and hypertrophied fibres are known to occur in dystrophia myotonica (Adams, Denny-Brown, and Pearson, 1962) it was quite likely that a size factor may have affected the experimental results but it was not possible to predict the direction or the magnitude of this influence.

In any event, such considerations would not invalidate the gross division of motor units into those which were completely destroyed and those which were still of appreciable size.

At this point the interpretation of the motor unit results may be conveniently summarized, as follows:

1. Denervation is present in EDB.

2. It is not due to methodological error-for example, undetected small units, see Results.

3 . It is not due to traumatic neuropathy.

4. It is not secondary to myopathy (substantial sizes of surviving units).

If the denervation is not secondary to a myopathy then only two possibilities remain. Either it is an independent phenomenon occurring in association with the primary myopathy responsible for dystrophy or alternatively muscular dystrophy is the result of a neuropathy. It is sufficient at the present time to state that, while the first possibility cannot be excluded, the second hypothesis has the merit of simplicity and is compatible with all the observed features of dystrophic muscle. This hypothesis of a primary neuropathic cause of muscular dystrophy has already been briefly considered (McComas, Sica, and Currie, 1971) and will be dealt with more fully in a subsequent paper.

We wish to thank Mr. C. Wallace, Mr. T. Blogg, and Mr. L. Smith for invaluable technical services and Mrs. Y. Chisholm for secretarial assistance. The work was supported by grants from the Medical Research Council, the Muscular Dystrophy Group of Great Britain, and the Muscular Dystrophy Associations of America, Inc. One of us (R.E.P.S.) held a British Council Scholarship.

\section{REFERENCES}

Adams, R. D., Denny-Brown, D., and Pearson, C. M. (1962). Diseases of Muscle. A Study in Pathology, 2nd edition. Harper: New York.

Campbell, M. J., McComas, A. J., and Sica, R. E. P. (1970). An electrophysiological study of dystrophia myotonica. J. Physiol. (Lond.), 209, 28-29P.

Coers, C., and Woolf, A. L. (1959). The Innervation of Muscle. Blackwell Scientific: Oxford.

Engel, W. K. (1966). Histochemistry of neuromuscular disease - significance of muscle fibre types. In Proceedings of the VIII International Congress of Neurology, Vienna 1965, Vol. 2, pp. 67-101. Wiener medizinische Akademie: Vienna.

McComas, A. J., Fawcett, P. R. W., Campbell, M. J., and Sica, R. E. P. (1971). Electrophysiological estimation of the number of motor units within a human muscle. $J$. Neurol. Neurosurg. Psychiat., 34, 121-131.

McComas, A. J., and Mrozek, K. (1967). Denervated muscle fibres in hereditary mouse dystrophy. J. Neurol. Neurosurg. Psychiat., 30, 526-530.

McComas, A. J., and Mrozek, K. (1968). The electrical properties of muscle fibre membranes in dystrophia myotonica and myotonia congenita. J. Neurol. Neurosurg. Psychiat., 31, 441-447.

McComas, A. J., Sica, R. E. P., Campbell, M. J., and Upton, A. R. M. (1971). Functional compensation in partially denervated muscles. J. Neurol. Neurosurg. Psychiat. In press.

McComas, A. J., Sica, R. E. P., and Currie, S. (1970). Muscular dystrophy: evidence for a neural factor? Nature (Lond.), 226, 1263-1264.

McComas, A. J., Sica, R. E. P., and Currie, S. (1971). An electrophysiological study of Duchenne dystrophy. $J$. Neurol. Neurosurg. Psychiat. In press.

MacDermot, V. (1961). The histology of the neuromuscular junction in dystrophia myotonica. Brain, 84, 75-84.

Ricker, K., and Mertens, H. G. (1968). Myasthenic reaction in primary muscle fibre disease. Electroenceph. clin. Neurophysiol., 25, 413-414.

Sica, R. E. P., and McComas, A. J. (1971). Fast and slow twitch units in a human muscle. J. Neurol. Neurosurg. Psychiat., 34, 113-120.

Sica, R. E. P., and McComas, A. J., (1971). An electrophysiological study of limb-girdle and facioscapulohumeral dystrophy. J. Neurol. Neurosurg. Psychiat. In press.

Slomić, A., Rosenfalck, A., and Buchthal, F. (1968). Electrical and mechanical responses of normal and myasthenic muscle, with particular reference to the staircase phenomenon. Brain Res., 10, 1-78 (special issue). 